\title{
The Concept of Nostalgia: Be Kind Rewind and the Reflection on the Case of ATV in Hong Kong 2015
}

\author{
Wendy Chan Wing Lam*, Wong Chi Hung
}

School of Communication, Hong Kong Baptist University, China

Copyright $\bigcirc 2016$ by authors, all rights reserved. Authors agree that this article remains permanently open access under the terms of the Creative Commons Attribution License 4.0 International License

\begin{abstract}
Be Kind Rewind, as spoken by the film's title, one may understand the trick that hides behind as Rewind is also associated with the same consonance Remind telling us a film that shares the collective memory of the public. The concept of the Society of Spectacle is brought forward by Guy Debord in 1970s, which he sheds lights on the class alienation, commodification of cultural products, Debord [7] as well as the role of mass media's metamorphosis in staging the so called "reality" on TV, is considered to be a mainstream channel in 1970s-1980s for people to obtain the news and enjoy entertainment. With this concept, we draw the central theme of discussing this with the film Be Kind Rewind in which it stages how the antique video rental store is forced to be demolished and the adventure that the new generation helps renew the product and share the collective memory, going back to the theme of commodity fetishism that Jappe [16] put forward. From the view point of Theodor Adorno, "in psycho-analysis nothing is true except the exaggeration" and for film as a product, it also echoes with the idea of fetishism that stated by Wall [22]. Here, the conflict of urbanization and modern development makes it an echo to the concept of the spectacle of making the class alienated through the commodification process of video rental store and also alienates the old people from the rapid development of the modern city. With the revival of reshooting the film with no budget, it connects closely to the concept of the work of art in the age of mechanical reproduction that Walter Benjamin put forward that the unique existence of the work of the art determined the history to which it was subject throughout the time of its existence, according to Benjamin [3]. Most importantly, while we watch this film, the real life example that happens in Hong Kong media industry would be Asia Television Limited (ATV) that they stage their "Rescue Our ATV Show" in order to save their company by attracting the "potential investors". While this case connects with the aforementioned film, we can see actually what happen in real life is the opposite. Nostalgia turns into a ridicule. From Jameson [15], postmodernism that the modernist engagement with art and culture is lost in the recycling of things, past full of sentiments, but devoid of the critique,
\end{abstract}

reflections. The television under such circumstance is not limited to provide information and showing the greatest entertainment programme but becomes a spectacle to ask for money yet not in a glamourous and commoditized manner. In light of this, this research is going to explore how mechanical reproduction alienates our society from the real life and how commodification of cultural product especially in Hong Kong TV industry make themselves become the spectacle in this day and age by carrying out content and textual analysis of the above mentioned cases. It would offer a theoretical contribution in which society of spectacle not only brings the success of TV industry but also actually polarizes the TV industry into the "mass" product and only through exposing its weakness to the audiences as to save the reputation and attract upcoming investors.

Keywords ATV, Commodification, Mechanical Reproduction, Nostalgia, Post Modernism, Society of Spectacle

\section{Introduction}

Be Kind Rewind, it is a film done by Michel Gondry, in which he connected the theme of redevelopment of the suburban area and the revolutionary changes of the film industry. Given that nowadays the people are routinized by the fact that with the advent of technology, we aim for delicate, extraordinary and spectacular films; on the other hand, we are lusting for the advancement and convenience of our surroundings. Highlighted by the opening scene of the film, the film brings about a key figure into the very beginning, who is the jazz singer, Fats Waller, who was once an influential American Jazz pianist and composer. With him as a fading out figure, but spirit remains in the old generation, it echoes the idea of nostalgia and the lust for fading and antique kind of music and arts forms. Certain films were "re-filmed" by the key actors of the film, the films range from Ghost Busters, Driving Miss Daisy, 
Robocop, Rush Hour 2, Lion King, Stanley Kubrick, 2001: A Space Odyssey. These films are the most popular in 1980s. In the age of $21^{\text {st }}$ century, only dates back to 20 years before, films still rely much on the manual filming and editing, yet, time fades swiftly, and these films products are no longer have their renting values and only very few of them would cherish these films, the "mom and pop store" as commented by the shop owner, has limited space for further development and survival. In light of this, the shop owners and the minimum numbers of worker in the video rental shops. The rental shops stand for all the fading materials under the domination of capitalist society. While operating the old shops in the mechanism of commercial industry. The shop owner wants to go on with the shop not because of how much profit he could earn in the end but to pass on the spirit of Fats Waller as his Jazz spirit and his old home was indeed situation at the video rental shop building. He does not have family and he is clearly a lonely old man with the videos and an old classic rewinding machine. These are all the materials that were considered to be worn out and obsolete in this day and age. Yet, in his eyes, this is more important than his life. Out of his persistence, this film touches on certain themes, from the age of mechanical reproduction that people can watch the films at home by renting or buying a video back home, the spectacle in the theme of commodity fetishism and here the film industry gradually enter the postmodern era in which the sense of pastiche towards the disappearance of the individual subject is found. For the case of Asian Television Limited (ATV), it is a local channel that was established in 1957 and it has been free for all these years. In recent years, the ownership changed from local investors to Chinese investors. Given this change, it is found that the operational system has been entirely different from the previous, the viewing rate dropped drastically and they have to face the bankruptcy. $A T V$ is a TV channel which serves Hong Kong for over 50 years and now it tries to save the TV channel by bring up the good old days yet it failed. It wants to get a survival by fund-raising through the $56^{\text {th }}$ Anniversary $A T V$ show. ATV is a TV channel wishes to survive by enlisting the supports from audiences and get the business running. Yet, for $B e$ Kind Rewind, it is not aiming at profits, its survival means a collective memory for Fats Waller as well as for the community. By co-creating a new film product to refrain from the coercive force of the urban development, it is a neighborhood memory and the kind of nostalgia that formed along the way could relate back to the old days, yet $A T V$ is deemed to be an epic fail. The film industry sacrificed the old community in order to see the "betterment" of the society, people do not come to the shop and discuss the film; on the other hand, people no longer want to watch ATV, one of the earliest TV channel in Hong Kong, due to a more fierce competition in the TV industry, in order to safeguard the this channel, the CEO came out and danced on the street, and they even put up a show to recollect the memory among the people, the theme of pastiche actually is found and highlighted in both cases.
Via these two examples, this article aims to build up the four arguments including how the contemporary world changes the way people watch film, forms a copy that could be shown in the cinema, to everyone could own a VCR at home, to in the form of DVD later the days. Therefore, the first theme is how mechanical reproduction changes the perception of film of the people; and the second theme is the sense of nostalgia for the good old days and collective memory, in which people found that the world is getting too fast, they started to notice that they have to keep the old against the new; society of spectacle when the fast development of products only put their emphasis on how to sell the product and present it in a spectacular way, and lastly, collective participation and re-creation' under the concept of pastiche, when they tried to mimic the old products. This article attempted to connect these four points together to argue that these four major segments in cultural studies have been drawn into the post-modern society, and see how entertainment industry, especially TV industry and film industry juggle with that.

\section{Literature Review}

\section{Society of the Spectacle}

"The commodity as spectacle" is common in this day and age. Everything seems connect with the capitalist society and the consciousness is the screen on which the regime of commodity movement carves its visceral speculations, and increasingly all things are absorbed by cinema (capital) and appear on (or disappear form), depending on what is required) the screen of perception, as put forward by Beller [2]. This kind of cinema would easily guide us to think of the term of commodity fetishism. The principle of commodity fetishism, the domination of society by things whose qualities are at the same time perceptible and imperceptible by the senses. The principle is absolutely fulfilled in the spectacle, where the perceptible world is replaced by a set of images that are superior to that world yet at the same time impose themselves as eminently perceptible, as said by Rigakos [21].

On the other hand, it is mentioned by Jappe [16] that the spectacle is both the outcome and the goal of the dominant mode of production and the economy should be therefore be understood as one portion of global human activity that holds sway over all the rest. The economy is an independent one and subjugated the human life and it echoes the idea with Debord that there is the triumph of the commodity within the prevailing mode of production.

"It is the world of the commodity ruling over all lived experience." Debord [7], so as the operation of cinema. It is argued that "The cinematic mode of production relies upon a tandem structuring of perception and organization that results in the commodification of each -capital becomes the arbiter of the value of various organizational forms. It does this in the intensification of the circulation of the commodity image...capital-cinema posits, finally the 
political economy of the society of spectacle, as mentioned by Beller [2].

\section{Mechanical Reproduction}

In the realm of mechanical reproduction, it emphasizes the mode of production as well as how people perceive the production. It is said, in the earlier day, the collective viewing experience and how this means of viewing enlighten and mobilize people Benjamin [3]. While talking about the mode of reproduction, in principle, a work of art has always been reproducible. According to Walter Benjamin, man-made artifacts could always be imitated by men. However, mechanical reproductions represent something new. Since reproduction of work of art lack its presence in time and space, unique existence of the work of art determined the history, for instance the painting of Mona Lisa and Van Gogh's work after his death. In addition, physical conditions over the years and various changes in its ownership

Effects would be men are under the rule of the machines. They are no longer autonomous. The presence of the original is the prerequisite to the concept of authenticity. Technical reproduction can put the copy of the original into situations which would be out of reach for the original itself. It is said that Walter Benjamin returns to the beginnings of photography, looking at long exposure portraiture to understand the fascination of the medium prior to its large-scale industrialization in which the historiographic impulse of the little history is to return to a moment in the past in an effort to recover the utopian potential that was held therein but dissipated by the passage of time, as mentioned by Balsom [1]. The kind of nostalgia to relate the past with the history is highlighted as such.

In addition, highlighted by Benjamin [3] that the greater the decrease in the social significance of an art form, the sharper the distinction between criticism and enjoyment by the public. Later, raised by Comolli [6] that in the argument of "camera site" that there is a confrontation occurs between two discourses, one which locates cinematic technology in ideology, the other which locates in science .... In both cases discourse of technicians on the one hand, attempts to elaborate a materialist theory of the cinema on the other -the example given is always that which produces the cinematic image, and it alone, considered from the sole point of view of optics. This paves a way in the exploring the relationship between the use of machines in producing work and the cinematic representation.

\section{Postmodernism in the Film}

The word postmodernity suggests a period that comes after the period of modernity. Post modernism covers a wide range of matters. According to Jameson [15], there were five symptoms of the postmodern, namely, a new depthlessness of the image (waning of the effect); a weakening of historicity (pastiche); a whole new type of emotional ground tone (hysterical sublime), a new relation to technology (geopolitical aesthetic) and a mutation in built space (cognitive mapping), as mentioned by Buchanan [14]. Among these five symptoms, pastiche well fits the discussion of the below argument that I wish to put forward in the discussion of film Be Kind Rewind and the case ATV in Hong Kong.

Pastiche is one of the main characteristics of cultural production in the age of postmodernism according to Fredric Jameson. It is in fact brought forward by Jameson that "Historicism" in fact effaces history. It is argued by him that precisely why postmodernism should be grasped as cultural dominant rather than a style in which it is a conception which allows for the presence and coexistence of a range of very different, yet subordinate, feature" , as emphasized by Buchanan [14]. Unlike Debord, he captures largely about the presence, yet for postmodernity period, the waning effect of historicity in fact in a way affects the "the concept of nostalgia/ passionate attachment" at least for three levels, they are the neo-historicism in architecture, cinematic nostalgia for the present, and the new form of the historical novel. In the light of cinematic nostalgia for the present, he explains that we are nostalgic for the lost presentness of the past, it is rather a glossy kind of past, like the one found in fashion shoots, conveyed via re-motivated symbols and objects of a particular period.

When the past is being represent through pastiche the result is a "loss of historicalness". Jameson believes it is a history founded on the pop images produces by commercial culture. Jameson [15] mentions that "nostalgia does not strike one as an altogether satisfactory word for such fascination (particularly when one thinks of the pain of a properly modernist nostalgia with a past beyond all but aesthetical retrieval), yet it directs our attention to what is a culturally far more generalized manifestation of the process in commercial art and taste, namely the so called "nostalgia film" (p. 66). Jameson is also aware the fact that the way reification and commodification dominates the culture and comprehension that interpretation must be rooted in a sense of history, as said by Roberts [20].

Since no certain conclusions has been drawn, this research aims to further explore how people in the film $B e$ Kind Rewind and the real life example happened in ATV deal with the theme of society spectacle that sacrifice the history of the community and the origin of company like ATV in this passage, mechanical reproduction that changes the nature of film and how these changes entail the theme of pastiche?

\section{Discussion}

\section{Mechanical Reproduction Changes the Perception of Film of the People}

People should be inseparable to the films and without people, the film is no longer a film. Undoubtedly, the quality of presence is always depreciated. By making many 
reproductions it substitutes a plurality of copies for a unique existence. In permitting the reproduction to meet the beholder or listener in his own particular situation, it reactivates the object reproduced. The uniqueness of a work of art is inseparable from its being imbedded in the fabric of tradition. This tradition itself is thoroughly alive and extremely changeable according to Benjamin [3]. In this film, it turns a topsy-turvy. The videos were mass produced, yet, there was only one copy from the shop. The customer could not own the video on their own, yet could rent them from the shop and seems they have demands from the people around the community. There seems creating a distance from the art work to the mass as they are "more like to wait in line to get into the cinema". Later, the videos" footage were erased and they create the videos on their own and it is not mass produced and in the market, there is only one copy for their filming, again, in this contemporary world, they go back to the point that mechanical reproduction is not that vibrant, more inclined to the fact the exhibition value is further enhanced by the demand from the customers. According to Benjamin, the cult value refers to its status and the rituals when you have a chance to look at the piece of arts, for example, people have to stand from the picture Mona Lisa from a distance; exhibition value refers to the content that a piece embedded, in which people could stop by the street arts and even touched it. It is further heightened by the fact that such kind of "reproduction" attract "a queue of the people" outside the shop where Jerry, the destroyer of the videos always throws up. The sarcasm, here lies, is that their work is outside the mechanism of reproduction though art is always reproducible according to Walter Benjamin, successfully attract people across the regions and almost form a "re-creation craze". How people perceive the reproduction of work is largely due to the fact that who produce it and how the production of work achieves the consensus among the public. The closing scene of the film highlights that the collective behavior of watching the unique production of work, "The story of Fats Waller" and there places a screen outside that everyone was gathered to watch the film together.

Further, the uniqueness of the artwork is referred as aura. The earliest art works originated in the service of a ritual, first the magic, then the religious kind. Its aura is never entirely separated from its ritual function. In this film, Fats Waller is portrayed to be the ritual figure, given that the shop owner could pass the shop to Mike. There are two things or even could claimed to be artwork in the film that are tightly connected with Fats Waller, one is the building itself, its existence, to Fletcher, is almost a memorial to Waller's trace. On the other hand, it is the film product made by the community, it is a collective memory for them. The building with the videos that rented by people is almost the symbolic existence of a piece of art work, people come to peek at the place and try to get the gist of what is going on inside. We could not deny the "aura" found in those recreations of the videos.

More important point to note, this film highlights that that old technique is replaced by new technique. It is crucial to see that people in the film treasure the old technique more than the new technique in which they still could manage to use the "antique" video player as well as the shop owner and Mike could manage to use the rewind machine unlike what we called today indexical arrangement of the film products, as said by Doane [9]. Yet the central theme of this film is not focusing on how they use the apparatus, but the reactions of the audiences. It is commented that mechanical reproduction of art changes the reaction of the masses toward art... the progressive reaction is characterized by the direct, intimate fusion of visual and emotional enjoyment. More than that, the decisive reason for this is that individual reactions are predetermined by the mass audience response they are about to produce, and this is nowhere more pronounced than in the film. Benjamin [3] mentions there is "the moment these responses become manifest they control each other" (p.234). It is undoubtedly the case of Be Kind Rewind, in which the people found the excitement, highlighted by the close shot of the people excitingly peeking through the window to watch the film "The Story of Fats Waller".

\section{Nostalgia for the Good Old Days and Collective Memory}

Argued by Jameson [15], "faced with these ultimate objects, our social, historical and existential present, and the past as referent, the incompatibility of a postmodernist "nostalgist" art language with genuine historicity becomes dramatically apparent. There are two different kinds of nostalgia for the film and $A T V$ respectively. The main contrast for them is that one falls into the trap of pastiche as frequently mentioned by Jameson, on the other hand, Be Kind Rewind in fact is more away from the trap of pastiche. Fletcher, the shop owner of the video rental shop connects the history of the Jazz singer Fats Waller with the reservation of the building. He does not regard the profits highly but the reservation of the building, while the urban developers persuaded him, he refuses to take their plan even they proposed a tempting offer. With the advent of technology, the betterment of the city, in the film, the urban developer came and said, "We will build the new apartment for the region and it will bring better scenery to the surrounding area."

On the other hand, the people living there, the aging group still habitually going to the shop to rent the movies out. The videos connect the community together and form the collective behavior and the "habits" and "entertainment" for the place in this rather backward region. "Nostalgia does not strike one as an altogether satisfactory word for such fascination, particularly when one thinks of the pain of a properly modernist nostalgia with a past beyond all but aesthetic retrieval, yet it directs our attention to what is culturally far more generalized manifestation of the process in commercial and taste, and namely the "nostalgia film" Jameson [15], p.66. Nostalgia is heightened by the different stakeholders. The shop owner, Fletcher, tried to save the 
building because he has spent years here and treated the building as his home and the community is his family as he does not get married; Mike, the employed labor working into the video rental shop as a young one still wants the building to be preserved at the last minute and even encouraged Fletcher to be involved in the filming for the film of Fats Waller. Jerry, the destroyer of the videos, wreck the power plant in order to keep the health of the people staying at the place and to act in the film in order to raise the money, they are there not to destroy the connection of the video rental shops with the community, they strived hard to preserve the building with a purpose.

In the end, the characters may start understand the significance of renting a film is that people found it as "limited copy" and they started to sense the demand. It actually echoes with Benjamin's argument in which one can make any number of prints; to ask for the authentic print makes no sense. The last scene of the movie shows that they shoot a film that is about their little region/ community in which it acts as authentic print and it is not about commercial at all. On the other hand, it is agreed by other scholars that that films reveal the underlying social attitudes and ideologies of the cultures that produce them, the ways film manipulate audience beliefs, and the ways they exploit and satisfy audience desires, according to Mast et al.[18]. In this film, Be Kind Rewind, the limited copies help the audiences reflect their emotion with the community whether urban development is needed.

It is mentioned that "pastiche is the imitation of a peculiar or unique style, but in contrast to parody or satire it is an imitation without a purpose, save that of the pleasure of reanimating a dead language" Buchanan [4]. For the case of ATV, recently (2015 April $14^{\text {th }}$ ), they are not guaranteed the bid to continue running the business by the government because of their no up to standard performance over the past years. Not long ago, they put up a show to rescue their lost audiences and strived to earn a survival. The show is called "ATV 56 $6^{\text {th }}$ Anniversary". Unfortunately, while they attempted to catch the public's attention, they only formed the society of spectacle that the adverse feedback is resulted. They displayed the masterpieces of the $A T V$ of the past to the people so as to arouse their interests again. However, such kind of "nostalgia" only aim at creating profits and neglecting the historicalness of $A T V$ and how it links to this day and age development for $A T V$. This disappointed the audiences because such spectacle pushes $A T V$ to the dead end. On the other hand, the current director of $A T V$, Wang Zheng, led the labors of $A T V$ danced outside the government office and even created slogans that aimed to catch the media's attention. Without a purpose, connect the nostalgia with the capitalist operation of the TV and it is deemed as the epic fail because historicism is essentially concerned with the problem of our relationship to the past, and of our possibility of understanding the latter's monuments, artifacts and traces, as put forward by Homer [14].

Pastiche, it is to celebrate the old idea, it is a technique to imitate the old and let the new generation know the past. Yet, for the $A T V$ and Be Kind Rewind, the staffs working in the film Be Kind Rewind wants to save the business by re-filming the films, and $A T V$ would like to put up the show on TV so as to remind people the good old days.

\section{Society of Spectacle: The Commodity Product Turns into a Ridicule}

Commodity fetishism is broadly understood as the masking of the social relationships underlying the process of production, to illuminate three invisibilities in the commodification of ecosystem services, as mentioned by Kosoy \& Corbera [19]. Such concept could connect closely to the case of Be Kind Rewind and ATV. ATV is exactly the case the antithetic to what we spot the film. Be Kind Rewind wants to keep the building and $A T V$ wants to save their business. Fund raises act by the movie is in fact a highlighting point and it is almost like a mirror to the case of $A T V$. Jerry, who appears to be a foul up friend in the whole story, is exactly portrayed as the same trick that made by the $A T V$. The act of camcorder by Jerry has in fact paved a way to the fact that they would turn to a ridicule in the end. With the case of $A T V$, we can see actually what happen in real life the opposite is. Nostalgia turns into a ridicule when it is formed in the spectacle.

The $A T V$ case is closer to the Jameson's argument against postmodernism that the modernist engagement with art and culture is lost in the recycling of things, past full of sentiments, but devoid of the critique, reflections that makes it a quick fall and even failed to gain the bid to run the business. It is said, "Parody finds itself without a vocation; it has lived, and that strange new thing pastiche slowly comes to take its place. Pastiche is, like parody, the imitation of a peculiar mask, speech in a dead language: but it is a neutral practice of such mimicry, without any of parody's ulterior motives, amputated of the satiric impulse, devoid of laughter and of any conviction that alongside the abnormal tongue you have momentarily borrowed, some healthy linguistic normality still exists." Jameson [15]. And this comments in fact echoes with what Debord [8] mentioned, "It is a particular society, not a particular technology that has made cinema what it is. Cinema could have been historical analyses, theories, essays, memories".

\section{Collective Participation and Re-creation}

Collective participation is activated by collective memory. There is a line from which Fletcher is being convinced by a stranger he met on the train for he is persuaded to follow the trend of the market. Later, he even started out the research during his trip to memorize Fletcher. Yet, he did turn to another though when he found Mike and Jerry tried hard to run the antique the video rental shop. With the opening scene displaying the graffiti of Fats Waller, the graffiti captured the attention of the public, the police and even the kids along the way would ask who he is. The setting of the films places the importance of the people first. By introducing the key figure, almost a soul of the film, Fats 
Waller in the beginning and till the end, Fats Waller reinstates his importance and the messages of the arts, no matter in the form of music or film. Time fades, yet the people's spirit should still be closely connected to the film. Films is produced for people or audiences to enjoy and so as the house is built for the comfort of the people. While we look at the collective memory in the contemporary world, if we would like to create the "memory", collective action would be the first step. This film tells us the collective memory give a reason for the collective participation. However, each collective participant would be part of the memory of the people. Film brings people together, so as the work being created brought the production team tightly and tried their best to produce a piece of good work.

Nowadays, though the film industry is thriving, yet there are still some limited spaces for the low-budget and relatively smaller scale film project to earn a survival. The format of YouTube in the so called new media is still the film outlets for a lot of small movies that done by people with limited budgets. In the vein of logic, actor represents himself to the public before the camera, rather than representing someone else. The projector will play his shadow before the public. For the first time, this is the effect of the film- man has to operate with his whole living person, yet forgoing its aura, as repeatedly emphasized by Benjamin [3], p.229. Facing the camera, one may understand he will face the public ultimately. The actor needs to offer his whole self, his heart and soul. Very often, the film responds to the aura with an artificial buildup of the personality outside the studio and the cult of the movie star is fostered by the money of the film in order to preserves the spell of personality and commodity. Yet, in this film, it is another story. They do not have money to build their personality. The kind of aura comes from the fact that the film is produced base on the setting of the community and the creativity that built up by Mike, Jerry and other characters, etc.

The key characters in the film become the actors and the directors together. The role of director and actors are always clear-cut. They try to capture the so called "real scene" for the film, yet what they are doing is actually truer than what other film portray. Everyone come to ask for the "re-make" of the film and become the huge hit. Yet, the last scene of the film shows the film screening session for the people, however, the film that displayed is an originally produced work after the ban from the government and it is what the community enjoys a lot. What does it imply to us? While we draw it into the context of film, the theme of pastiche that picked from the "symptoms" of postmodernism is the trap that we should not fall when we think of nostalgia because historicalness would attach the utmost importance in the end.

\section{Conclusions}

Benjamin [3] comments that masses seek distraction whereas art demands concentration from the spectator, the film as an art form should play a role as such. However, film in various forms, could be shown in VCR or in DVD and no longer limited to the screen playing in the cinema and the role of movie to draw the people together would be lesser. The reception could be individual with the advent of technology. While with the advent of technology, the spectacle in the sense that attract people by the fact that large scale film production would be seen as another facet of money and commodities are now that there is to see; the world we see is the world of commodity, as emphasized by Debord [7]. The product that presented would be more of the effect rather than the nature of film in which message should weigh far more important than the means to an end. It is important to note that there is a great potential to computer media in general as the storage media becomes active that is the operation of searching, sorting, filtering, indexing and classifying, Manovich [17] that makes a huge contrast to the "production" that the film intends to present to us.

The juxtaposition between the film and the experience is a narration that it reflects certain reality of the film industry and even TV industry. Again, the cultural domination would be more serious in this day and age for it is said postmodernism is the new cultural form of our age, as concluded by Jameson [15]. Therefore, the nostalgia that grows from the film industry and how the film work would be affected for sure in the long run.

\section{Acknowledgements}

I am very much obliged to Professor Emilie Yeh for her very useful comments and suggestions on an earlier version of this piece.

\section{REFERENCES}

[1] Balsom, E. (2009). A cinema in the gallery, a cinema in ruins. Screen, 50(4), 411-427.

[2] Beller, J. (2012). The cinematic mode of production: attention economy and the society of the spectacle. University Press of New England Hanover and London.

[3] Benjamin, W. (1968). Illuminations. Translated by Harry Zohn. Edited by Hannah Arendt. New York: Schocken.

[4] Buchanan, I. (2006). Fredric Jameson: live theory. Continuum International Publishing Group.

[5] Buchanan, I. \& Irr, C. (Ed.). (2006). On Jameson: From Postmodernism to Globalization. State University of New York Press.

[6] Comolli, J. L. (1980). Machines of the Visible. The cinematic apparatus, 121-142.

[7] Debord, G. (1967). The society of the spectacle. Translated by Donald Nichoison-Smith. New York: Zone Books. 
[8] Debord. G. (1978). Guy Debord, Complete Cinematic Works: Scripts, Stills, Documents, trans. Ken Knabb (Oakland, CA: AK Press, 2003), pp. 145-46 (translation modified).

[9] Doane, M. A. (2007). The indexical and the concept of medium specificity. Journal of Feminist Cultural Studies, $18(1), 128-152$.

[10] Elsaesser, T. (2008). "Afterword: Digital cinema and the apparatus: archaeologies, epistemologies, ontologies" in Bruce Bennett, Marc Furstenau, and Adrian MacKenzie (eds.), Cinema and Technology: Cultures, Theories, Practices (Houndmills: Palgrave/ MacMillan, 2008), 226-240.

[11] Flew, T. (2011). The creative industries: culture and policy. Sage.

[12] Grainge, P. (1999). Reclaiming heritage: colourization, culture wars and the politics of nostalgia. Cultural Studies, 13(4), 621-638.

[13] Gunning, T. (2007). Moving away from the index: Cinema and the impression of reality. Journal of Feminist Cultural Studies, 18(1), 29-52.
[14] Homer, S. (1998). Fredric Jameson: Marxism, Hermeneutics, Postmodernism. Taylor \& Francis.

[15] Jameson, F. (1984). Postmodernism or the cultural logic of late capitalism. Studies, 29, 54.

[16] Jappe, A. (1999). Guy Debord. University of California Press.

[17] Manovich, L. (2002). Old media as new media: cinema. The New Media Book, 209-218.

[18] Mast, G., Cohen, M., \& Braudy, L. (1992). Film theory and criticism: Introductory readings. Oxford University Press.

[19] Kosoy, N., \& Corbera, E. (2010). Payments for ecosystem services as commodity fetishism. Ecological economics, 69(6), 1228-1236.

[20] Roberts, A. C. (2000). Fredric Jameson. London and New York: Routledge.

[21] Rigakos, G. (2008). Nightclub: Bouncers, risk, and the spectacle of consumption. McGill-Queen's Press-MQUP.

[22] Wall, B. (2013). Theodor Adorno and Film Theory: The Fingerprint of Spirit. Palgrave Macmillan. 